\title{
Comparison of the Clinical Characteristics and Outcomes between Leprosy- Affected Persons in Sorokdo and the General Population Affected by Chronic Hepatitis C in Korea
}

\author{
Young-Hwan Ahn ${ }^{1}$, Hyungcheol Park ${ }^{2}$, Myeon Jae Lee ${ }^{3}$, Dong Hyun Kim ${ }^{3}$, Sung Bum Cho ${ }^{3}$, Eunae Cho ${ }^{3}$, Chung Hwan Jun ${ }^{3}$, \\ and Sung Kyu Choi ${ }^{3}$ \\ Departments of ${ }^{1}$ Internal Medicine and ${ }^{2}$ Preventive Medicine, Sorokdo National Hospital, Goheung, and ${ }^{3}$ Department of Gastroenterology, \\ Chonnam National University Hospital, Gwangju, Korea
}

Background/Aims: Patients with Hansen's disease are the most vulnerable to hepatitis $\mathrm{C}$. However, no data on the treatment efficacy of direct-acting antiviral agents (DAAs) are available in this group. Therefore, we elucidated the prevalence and clinical outcomes of hepatitis $\mathrm{C}$ in persons affected by leprosy in Sorokdo, Jeollanam-do, Korea. Methods: We retrospectively included 50 leprosy patients with positive hepatitis $\mathrm{C}$ virus (HCV) RNA test results (group A) hospitalized at the Sorokdo National Hospital from May 2016 to March 2018 and 73 patients with chronic hepatitis C who were treated with DAAs at the Chonnam National University Hospital (group B) from May 2016 to December 2017. Results: Overall, at the Sorokdo National Hospital, positive HCV antibody and HCV RNA rates were 18.4\% and $11.0 \%$, respectively. The mean participant age was $76.5 \pm 7$ years, and $58 \%$ of participants were men. The genotypes were type 1b in 44\% (22 out of 50) and type 2 in 56\% (28 out of 50). Sustained virologic response was achieved at a rate of $95.5 \%(21 / 22)$ in genotype 1 b and $92.9 \%(26 / 28)$ in genotype 2 patients. Ribavirin-induced hemolytic anemia occurred in 57.1\% (16/28) of patients with genotype 2 . Among these, $28.5 \%$ (8/28) received blood transfusions. Conclusions: Treatment efficacy was not different between the leprosy-affected population and the general population. However, severe ribavirin-induced hemolytic anemia requiring transfusion was present in $28.5 \%$ of genotype 2 patients. Therefore, we suggest ribavirin-free DAAs for the treatment of genotype 2 hepatitis $C$ in leprosy-affected persons in the future. (Gut Liver 2019;13:549-556 )
Key Words: Hepatitis C, chronic; Antiviral agents; Leprosy

\section{INTRODUCTION}

Approximately 71 million people have hepatitis $\mathrm{C}$ virus (HCV) infection worldwide. ${ }^{1}$ Hepatitis $\mathrm{C}$ is a leading cause of liver cirrhosis, hepatic failure, and hepatocellular carcinoma (HCC). ${ }^{2-5}$ Recently, reports of infection among various groups from several medical institutions and the introduction of direct-acting antiviral agents (DAAs) have increased interest in hepatitis C in South Korea. ${ }^{6}$ Previously, the only treatment option for HCV was peg-interferon plus ribavirin (PR). Combination therapy with PR has been approved and prescribed since 2001, but flulike symptoms and hemolytic anemia have made it difficult to complete the treatment. ${ }^{7-10}$ The achievement rate of sustained virologic response (SVR) was also unsatisfactory (42\% to $46 \%$ in genotype 1 and $76 \%$ to $82 \%$ in genotypes 2 or 3$)^{11,12}$ despite the efforts of physicians and patients who experience adverse effects of the PR treatment. In this situation, DAA therapy, first introduced in 2013, showed greater efficacy with shorter treatment periods, and lower rates of side effects compared to the classical treatment based on PR. Various DAAs have been introduced and applied as treatment for infections caused by various HCV genotypes. ${ }^{13}$

According to the 2016 Korean Association for the Study of the Liver (KASL) guidelines, ${ }^{14}$ the standard therapies for HCV genotype 1 are ledipasvir/sofosbuvir (SOF) for 12 weeks, as well as ombitasvir/paritaprevir/ritonavir plus dasabuvir, daclatasvir (DCV) plus SOF, and SOF plus simeprevir with or without weight-based ribavirin for 12,12 to 24 , and 12 to 24 weeks,

Correspondence to: Chung Hwan Jun ${ }^{\mathrm{a}}$ and Sung Kyu Choi ${ }^{\mathrm{b}}$

Department of Gastroenterology, Chonnam National University Hospital, 42 Jebong-ro, Dong-gu, Gwangju 61469, Korea

${ }^{a}$ Tel: +82-62-220-6296, Fax: +82-62-220-8578, E-mail: estevanj@naver.com

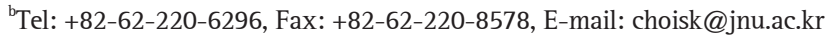

Received on September 27, 2018. Revised on December 4, 2018. Accepted on December 13, 2018. Published online May 27, 2019 pISSN 1976-2283 eISSN 2005-1212 https://doi.org/10.5009/gnl18432

@. This is an Open Access article distributed under the terms of the Creative Commons Attribution Non-Commercial License (http://creativecommons.org/licenses/by-nc/4.0) which permits unrestricted non-commercial use, distribution, and reproduction in any medium, provided the original work is properly cited. 
respectively; PR for 24 to 48 weeks is also recommended. A 24week combination therapy with DCV and asunaprevir (ASV) is recommended for genotype $1 \mathrm{~b}$ patients with no resistanceassociated substitution (RAS). Standard therapies for HCV genotype 2 are 12 to 16 weeks of SOF plus ribavirin, or DCV plus SOF for 12 weeks, and PR for 16 to 24 weeks. In the recently updated 2017 KASL guidelines, newer DAAs, such as elbasvir/ grazoprevir, SOF/velpatasvir, SOF/velpatasvir/voxilaprevir, and glecaprevir/pibrentasvir regimens, have been added..$^{13}$

In Korea, the positivity rates of hepatitis $\mathrm{C}$ antibody (HCV Ab) (0.4\% to $2.07 \%$ ) and HCV prevalence vary by region; the Jeollanam-do province has the highest HCV prevalence in South Korea. ${ }^{15-17}$ Previous data from South Korea showed a prevalence of HCV among leprosy-affected persons of approximately 16.6\% to $67.7 \%$. $^{18-20}$

However, there are no recent data about the prevalence and treatment efficacy of the standard therapy in leprosy-affected persons who are highly vulnerable to hepatitis C. ${ }^{14}$ In South Korea, currently 10,000 leprosy-affected persons are estimated to live in 87 settlements and seven residential facilities. ${ }^{21}$ However, those who are socially underprivileged have no proper chance of DAA treatment. Leprosy-affected persons often refuse treatment for hepatitis $\mathrm{C}$, because they have a strong negative perception of the word "infection." Furthermore, physicians who treat these patients tend to hesitate to prescribe ribavirin due to dapsone-related adverse effects and toxicities. Dapsone may cause hemolytic anemia, jaundice, and exfoliative dermatitis, which may be fatal if untreated..$^{22,23}$

To the best of our knowledge, no data have been reported on the treatment efficacy of DAAs for hepatitis C in leprosy-affected persons. Therefore, we aimed to elucidate the prevalence and clinical outcomes of hepatitis C in leprosy-affected persons at the Sorokdo National Hospital, a settlement/residential facility. We evaluated whether a significant difference existed between two hepatitis C-affected groups as follows: leprosy-affected persons from the Sorokdo National Hospital and the general patient population from the Chonnam National University Hospital.

\section{MATERIALS AND METHODS}

\section{Ethics statement}

This study was approved by the Institutional Review Board of Masan National Tuberculosis Hospital, Republic of Korea (approval number: IRB-398837-2018-E05). All work was carried out in compliance with the Ethical Principles for Medical Research Involving Human Subjects outlined in the Helsinki Declaration in 1975 (revised in 2000). Informed consent requirement was waived because the patient data were de-identified.

\section{Study subjects}

We retrospectively reviewed the medical records of 511 leprosy-affected persons (including current patients and prior patients declared completely cured) who were hospitalized at the Sorokdo National Hospital (Goheung, Jeollanam-do, Korea) from May 2016 to March 2018. All leprosy-affected persons in the Sorokdo region are registered at this Hospital. We enlisted 56 patients with a positive HCV RNA test, of whom 50 were included in this study. Patients with incurable malignant tumors $(n=3)$, over 90 years of age $(n=2)$, and those who refused treatment $(n=1)$ were excluded. According to the KASL guidelines at the time of patient enrollment, 17 patients (genotype 1b, RAS negative) were treated with DCV and ASV, three patients (genotype $1 \mathrm{~b}$, RAS positive) were treated with DCV plus SOF, two patients (genotype $1 \mathrm{~b}$, Child-Pugh class B) were treated with DCV plus SOF plus ribavirin, and 28 patients (genotype $2 \mathrm{a} / \mathrm{c}[\mathrm{n}=1]$ and $2 \mathrm{a}[\mathrm{n}=27])$ were treated with SOF plus ribavirin.

According to the KASL guidelines, the standard dosage of ribavirin is 1,200 and $1,000 \mathrm{mg} /$ day for body weight $\geq 75 \mathrm{~kg}$ and $<75 \mathrm{~kg}$, respectively. During the early phases of treatment, a standard dose of ribavirin given to leprosy-affected patients caused severe hemolytic anemia that required transfusion; thus, patients were afraid of using ribavirin. Therefore, we commenced ribavirin dose reduction as follows: 1,000 and $800 \mathrm{mg} /$ day for body weight $\geq 75 \mathrm{~kg}$ and $<75 \mathrm{~kg}$, respectively.

At the Chonnam National University Hospital (Gwangju, Jeollanam-do, Korea), 73 chronic hepatitis C patients treated with DAAs between May 2016 and December 2017 were enlisted. Of the 73 patients, 35 and 38 had genotype $1 \mathrm{~b}$ and 2 infections, respectively. The exclusion criteria were as mentioned above; however, those aged $<60$ years were also excluded because there were no such patients at the Sorokdo National Hospital. The treatment regimen for each genotype was based on the KASL guidelines at the time, and was similar to that at the Sorokdo National Hospital. RAS negative genotype $1 \mathrm{~b}$ patients were treated with DCV and ASV, and RAS positive genotype $1 \mathrm{~b}$ patients were treated with DCV plus SOF. Genotype 2 patients were treated with SOF plus ribavirin.

\section{Clinical and laboratory assessment}

Information on hepatitis B, HCC, previous treatment history, leprosy type, settlement duration in Sorokdo, and comorbidities were retrieved from pretreatment medical records. Starting at DAA treatment initiation, acquisition status and the numbers of patients with the following conditions were obtained from medical record data: elevated liver enzymes, decreased hemoglobin, required ribavirin dose reduction, required blood cell transfusion, experienced side effects, rapid virologic response (RVR), end-of-treatment response (ETR), and SVR. During hepatitis C treatment, blood tests including complete blood count, routine chemistry, prothrombin time, and HCV RNA titer were conducted at baseline, 4-week intervals during the treatment period, end of treatment, and at 12 or 24 weeks after treatment completion. Liver cirrhosis occurrence was evaluated using abdominal ultrasonography or computed tomography. 


\section{HCV RNA measurement and treatment efficacy assess- ment}

HCV RNA was measured using the COBAS TaqMan HCV assay version 2.0 (Roche Diagnostics, Tokyo, Japan), and the lower limit of quantification of HCV RNA was $15 \mathrm{IU} / \mathrm{mL}$ at all centers. Viral breakthrough was defined as an increase in HCV RNA $>1 \log _{10}$ from the nadir or HCV RNA greater than or equal to the lower limit of quantification, as detected after HCV RNA was previously undetectable. Positive ETR was defined as undetectable HCV RNA at the end of 12 to 16 weeks of treatment, while SVR was defined as undetectable HCV RNA at 12 or 24 weeks after treatment according to KASL guidelines.

\section{Statistical analysis}

The SPSS software version 21 (IBM Corp., Armonk, NY, USA) was used for all analyses. The chi-square test or Fisher exact test was applied for categorical data, and the Student t-test was used for continuous data. We determined the 95\% confidence interval (CI) of each variable from the mean and standard deviation. A p-value $<0.05$ was deemed to indicate statistical significance.

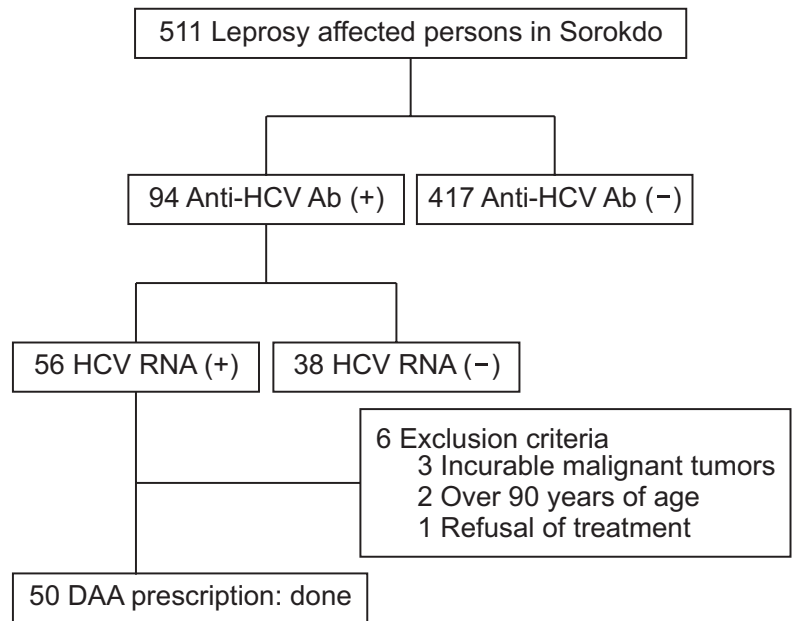

Fig. 1. Flow diagram of subject enrollment. $\mathrm{HCV}$, hepatitis C virus; Ab, antibody; DAAs, direct-acting antiviral agents.

Table 1. Intergroup Analysis of Baseline Characteristic Differences between Two Hospital Patient Populations

\begin{tabular}{|c|c|c|c|}
\hline Variable & Sorokdo National Hospital & Chonnam National University Hospital & p-value \\
\hline Male sex & $29(58.0)$ & $36(49.3)$ & 0.343 \\
\hline Age, yr & $76.58 \pm 7.05$ & $68.27 \pm 5.50$ & 0.048 \\
\hline Age in genotype 2, yr & $75.68 \pm 7.18$ & $69.10 \pm 5.29$ & 0.090 \\
\hline Body weight, kg & $54.98 \pm 12.72$ & $57.20 \pm 9.66$ & 0.194 \\
\hline Previous interferon-based treatment & $2(4.0)$ & $18(24.7)$ & 0.002 \\
\hline HBs Ag (+) & 0 & $1(1.3)$ & 0.363 \\
\hline Anti-HBs Ab (+) & $16(32.0)$ & $34(46.5)$ & 0.010 \\
\hline HCV RNA titer, $10^{6} \log \mathrm{IU} / \mathrm{mL}$ & $1.93 \pm 2.48$ & $1.33 \pm 1.37$ & 0.012 \\
\hline \multicolumn{4}{|l|}{ HCV genotype } \\
\hline $1 \mathrm{~b}$ & $22(44.0)$ & $35(47.94)$ & - \\
\hline $2 \mathrm{a}$ & $27(54.0)$ & 19 (26.03) & - \\
\hline $2 a / c$ & $1(2.0)$ & $19(26.03)$ & - \\
\hline Liver cirrhosis & $14(28.0)$ & $23(31.5)$ & 0.641 \\
\hline Child-Pugh score & $5.42 \pm 0.57$ & $5.10 \pm 0.40$ & 0.000 \\
\hline MELD score ${ }^{\S}$ & $8.02 \pm 3.15$ & $7.79 \pm 1.70$ & 0.000 \\
\hline Hemoglobin, g/dL & $12.28 \pm 1.56$ & $13.48 \pm 1.19$ & 0.134 \\
\hline \multicolumn{4}{|l|}{ Subgroup analysis of genotype 2} \\
\hline Hemoglobin, g/dL & $12.20 \pm 1.78$ & $13.40 \pm 1.16$ & 0.055 \\
\hline A proportion of $\mathrm{Hb}$ level of $14 \mathrm{~g} / \mathrm{dL}$ or more & $4(14.3)$ & $16(42.1)$ & 0.015 \\
\hline Platelet, $10^{3} / \mu \mathrm{L}$ & $177.68 \pm 67.22$ & $144.15 \pm 57.99$ & 0.181 \\
\hline AST, IU/L & $39.62 \pm 27.65$ & $63.62 \pm 35.86$ & 0.037 \\
\hline ALT, IU/L & $23.62 \pm 18.60$ & $39.60 \pm 36.61$ & 0.016 \\
\hline Total bilirubin, mg/dL & $0.65 \pm 0.34$ & $0.81 \pm 0.32$ & 0.466 \\
\hline
\end{tabular}

Data are presented as number (\%) or mean \pm SD.

HBs Ag, hepatitis B surface antigen; HBs Ab, hepatitis B surface antibody; HCV, hepatitis C virus; MELD, Model for End-Stage Liver Disease; AST, aspartate transaminase; ALT, alanine aminotransferase. 


\section{RESULTS}

\section{Demographics of the Sorokdo population}

Fig. 1 outlines the patients' flow in the study. The mean age of the Sorokdo population was $75 \pm 9.5$ years, and 51.3\% were men. HCV Ab, HCV RNA, and hepatitis B virus surface antigen detection rates were was 18.4\%, 11.0\%, and 2.3\%, respectively. HCC was diagnosed in $1.0 \%$ of the Sorokdo population.

\section{Clinical characteristics of study subjects at Sorokdo Na- tional Hospital}

The mean age of the 50 study participants was $76.5 \pm 7$ years, 58\% were men, 22 (44\%) showed genotype 1b, and 28 (56\%) showed genotype $2 \mathrm{HCV}$. Before DAA treatment, 54\% of the patients had HCV RNA level of $>6 \log _{10} \mathrm{IU} / \mathrm{mL}$. Liver cirrhosis was diagnosed in $28 \%$, whereas one patient (2\%) was diagnosed with HCC, and received radiofrequency ablation therapy. Sixteen patients (32\%) had positive HBsAb tests, and the prevalence of HBV co-infection was $0 \%$.

Among the leprosy subtypes, lepromatous leprosy was the most common, with a rate of 54\%, followed by tuberculoid leprosy (42\%), borderline leprosy (4\%), and intermediate leprosy $(0 \%)$. Hypertension (68\%) was the most common comorbidity, followed by diabetes (34\%), and cerebrovascular disease (16\%). The results of other laboratory findings are shown in Table 1.

\section{Treatment response and adverse events}

SVR rates of 95.5\% in genotype 1b (21/22) and 92.9\% in genotype 2 patients (26/28) were achieved. There was one treatment failure among genotype $1 \mathrm{~b}$ patients. The patient had no previous treatment history and received DCV and ASV combination therapy. She acquired RVR but showed virologic breakthrough at 2 months. There were two treatment failures in the genotype 2 group; while both cases showed liver cirrhosis, one was diagnosed with esophageal varices and Child-Pugh class A cirrhosis, and had previous treatment history. We treated her for
16 weeks, but failed to achieve a cure (Table 2).

During the treatment period, $12 \%$ of patients (6/50) had increased alanine aminotransferase (ALT) levels of $>1.5$ times the baseline levels, but all were within the normal range and were never $>5$ times above the baseline. Only one case $(1 / 50,2 \%)$ had an increase in the Child-Pugh score. In the genotype 2 group, the percentage of patients with ribavirin-induced hemolytic anemia was 57.1\% (16/28), and 28.5\% (8/28) received blood transfusions because their hemoglobin levels decreased below $8 \mathrm{~g} / \mathrm{dL}$. They were prescribed reduced ribavirin doses and completed the treatment (Table 3). In addition, no cases terminated treatment due to intolerance or side effects. Of the five patients administered dapsone in this cohort, one $(1 / 5,20 \%)$ had anemia during the treatment period.

\section{Comparison with hepatitis $\mathrm{C}$ patients in the general population}

Table 1 shows the differences in intergroup baseline characteristics between the Sorokdo National Hospital and the Chon-

Table 2. Comparison of Treatment Results from the Intergroup Analysis between Two Hospital Patient Populations

\begin{tabular}{lccc}
\hline & $\begin{array}{c}\text { Sorokdo National } \\
\text { Hospital }\end{array}$ & $\begin{array}{c}\text { Chonnam National } \\
\text { University Hospital }\end{array}$ & p-value \\
\hline Genotype 1b & & & \\
RVR & $21(95.5)$ & $30(85.7)$ & 0.243 \\
ETR & $21(95.5)$ & $32(91.4)$ & 0.562 \\
SVR & $21(95.5)$ & $31(88.6)$ & 0.371 \\
Genotype 2 & & & \\
RVR & $28(100.0)$ & $38(100.0)$ & - \\
ETR & $27(96.4)$ & $38(100.0)$ & 0.240 \\
SVR & $26(92.9)$ & $38(100.0)$ & 0.094 \\
\hline
\end{tabular}

Data are presented as number (\%).

RVR, rapid virologic response; ETR, end-of-treatment response; SVR, sustained virologic response.

Table 3. Comparison of Adverse Events in Genotype 1b Patients from the Intergroup Analysis between Two Hospital Patient Populations

\begin{tabular}{|c|c|c|c|}
\hline Adverse event & Sorokdo National Hospital & Chonnam National University Hospital & $\mathrm{p}$-value \\
\hline \multicolumn{4}{|l|}{ Genotype $1 \mathrm{~b}$} \\
\hline ALT $>1.5 \times$ baseline & $1(4.5)$ & $5(14.3)$ & 0.489 \\
\hline ALT $>5 \times$ baseline & 0 & 0 & - \\
\hline Elevation of the Child-Pugh score & 0 & 0 & - \\
\hline \multicolumn{4}{|l|}{ Genotype 2} \\
\hline ALT $>1.5 \times$ baseline & $5(17.8)$ & $4(10.5)$ & 0.358 \\
\hline ALT $>5 \times$ baseline & 0 & 0 & - \\
\hline Elevation of the Child-Pugh score & $1(3.6)$ & 0 & 0.232 \\
\hline Required blood cell transfusion & $8(28.5)$ & 0 & 0.000 \\
\hline Required ribavirin dose reduction & $13(46.4)$ & $4(10.5)$ & 0.001 \\
\hline
\end{tabular}

Data are presented as number (\%).

ALT, alanine aminotransferase. 
nam National University Hospital patients. Age, HCV RNA titer, Child-Pugh score, Model for End-Stage Liver Disease score, and serum creatinine were higher in the Sorokdo National Hospital patients $(\mathrm{p}<0.05)$, while aspartate aminotransferase, ALT, and HBsAb positivity were higher in the Chonnam National University Hospital patients $(\mathrm{p}<0.05)$. Body weight, hemoglobin, platelet, total bilirubin, albumin, sex ratio, hepatitis B prevalence, liver cirrhosis, and frequency of ALT and the Child-Pugh score elevation during the treatment period were not significantly different between the two hospitals. RVR, ETR, and SVR achievement did not significantly differ between the two hospitals, regardless of genotype (Table 2). However, in the genotype 2 group, the number of patients who required ribavirin dose reduction (46.4\% vs 10.5\%, p=0.001) and blood cell transfusion $(28.5 \%$ vs $0 \%, \mathrm{p}<0.001)$ were higher in the Sorokdo National Hospital patients (Table 3). The maximal changes in hemoglobin levels during the treatment period (mean \pm SD: $2.99 \pm 1.90 \mathrm{~g} /$
$\mathrm{dL}$ vs $2.28 \pm 0.96 \mathrm{~g} / \mathrm{dL}, \mathrm{p}<0.001)$ were also significantly different between the two hospitals (Fig. 2).

\section{DISCUSSION}

This study, conducted among the largest settlement of domestic leprosy-affected persons in Sorokdo, reveals the hepatitis C infection status in leprosy-affected persons in Korea and may help prevent liver cirrhosis and HCC in this population.

In 1997, Choi ${ }^{19}$ reported a 67.6\% (65/96) prevalence of HCV $\mathrm{Ab}$ in leprosy-affected persons in Busan and Gyeongsangnamdo settlements in Korea. In 2006, Choi et al. ${ }^{18}$ reported a prevalence of 30.6\% (45/147) and 28.8\% (41/147) for HCV Ab and HCV RNA, respectively, at the Sorokdo National Hospital. Studies conducted in leprosy-affected persons in Japan have reported a HCV Ab prevalence of 9.5\% to 30\%. ${ }^{24,25}$

Seong et al., ${ }^{26}$ in an attempt to determine the route of hepa-
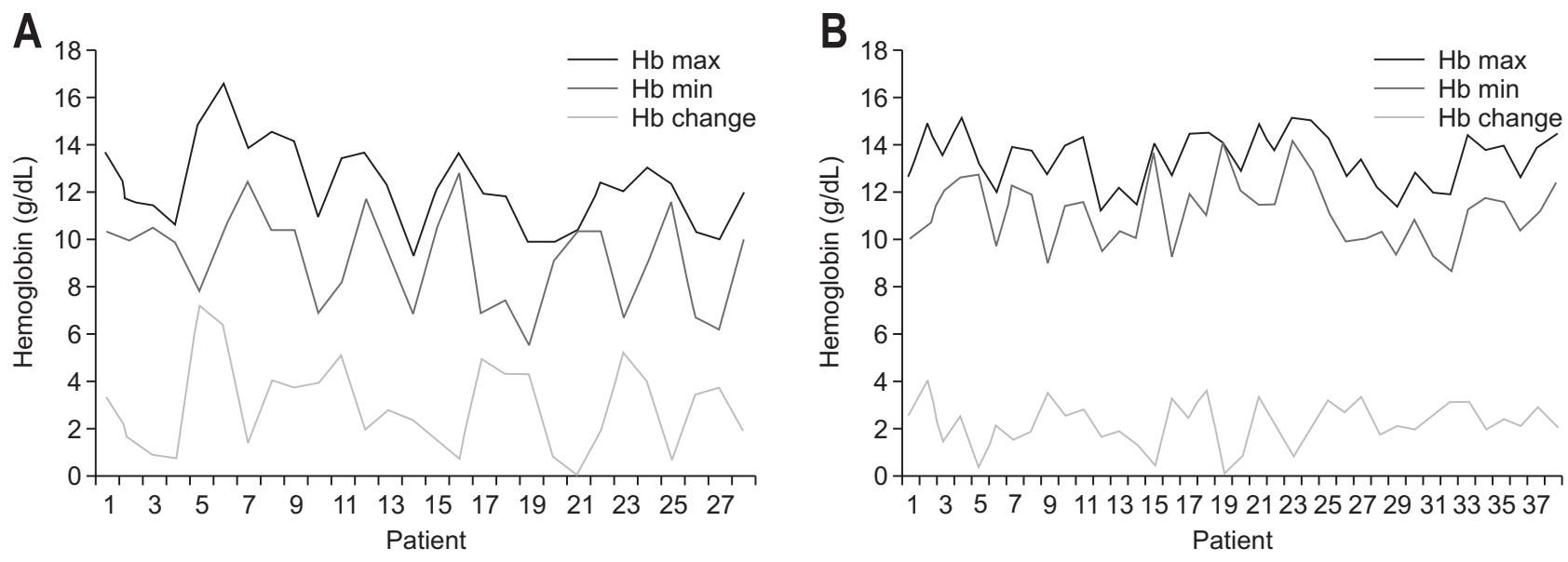

Fig. 2. Comparison of changes in hemoglobin level during the treatment period between the Sorokdo National Hospital (A) and Chonnam National University Hospital (B) patient populations.

$\mathrm{Hb}$, hemoglobin; max, maximum; min, minimum.
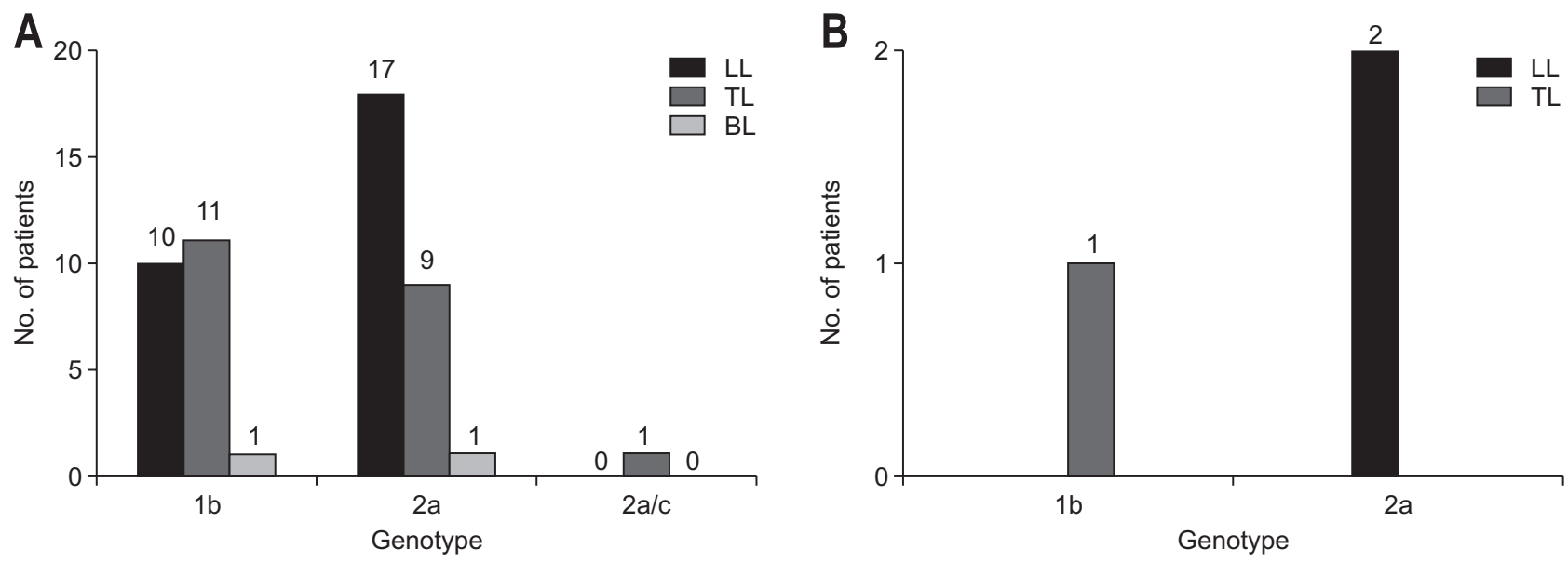

Fig. 3. (A) Prevalence of leprosy subtype in each hepatitis C virus genotype subgroup. (B) The genotype of three patients with treatment failure and their leprosy subtypes.

LL, lepromatous leprosy; TL, tuberculoid leprosy; BL, borderline leprosy. 
titis C infection, discovered that old age, intravenous drug use, needle-stick injury, transfusion before 1995, and tattoos were independent risk factors of HCV infection. Though we attempted to determine the cause of the high incidence of hepatitis $\mathrm{C}$ in leprosy-affected persons, no clear evidence was found based on data from past medical records. However, we found a possible infection route based on patients' statements and medical supplies housed in the Sorokdo Historical Museum. Patients indicated that in the past, they had limited supplies and thus shared medical knives, syringes, and bloody bandages. Disinfection devices were lacking, and when a patient died, the medical supplies were re-used for other patients. Items supporting their statements are displayed in the museum. In the present study, HCV Ab and HCV RNA prevalence in leprosy-affected persons was $18.4 \%$ and $11.0 \%$, respectively, which is much lower than that from the previous 10 to 20 years.

According to leprosy subtypes, HCV prevalence was highest with tuberculoid leprosy (15.4\%, 21/136 patients), followed by that with lepromatous leprosy $(8.2 \%, 27 / 327)$, borderline leprosy $(4.7 \%, 2 / 42)$, and intermediate leprosy $(0 \%, 0 / 6)$. Interestingly, cellular immunity is relatively active in tuberculoid leprosy but not in lepromatous leprosy. ${ }^{27,28}$ The pattern of leprosy subtype rates obtained in our study is comparable to that reported by Egawa et al., ${ }^{24}$ with no significant difference in HCV prevalence among subtypes. Fig. 3 shows detailed information of leprosy subtypes by HCV genotypes.

DCV and ASV were mainly used for treating genotype $1 \mathrm{~b}$ patients in this study. SVR achievement rate was 95.5\% at the Sorokdo National Hospital and 88.6\% at the Chonnam National University Hospital. Manns et al. ${ }^{29}$ reported an SVR achievement rate of 90\% for DCV and ASV treatment (24-week regimen) in 21 genotype $1 \mathrm{~b}$ treatment-naive patients. Another study (combining five studies) reported a 93.9\% SVR achievement rate in patients with a negative RAS mutation status before treatment. ${ }^{30}$ The SVR rate in Korean, Taiwanese, and other Asian treatmentnaïve patients receiving DCV plus ASV for genotype $1 \mathrm{~b}$ infection was 92.3\%. ${ }^{31}$ Compared with this previous study, the SVR rate of DCV and ASV combination therapy for genotype $1 \mathrm{~b}$ leprosy-affected persons in this study was superior. There are several possible explanations as to why genotype $1 \mathrm{~b}$ patients in this cohort showed a relatively high SVR rate. First, since a positive RAS test result is associated with low SVR rate, ${ }^{30}$ we performed a comprehensive pretreatment RAS test. We detected signature resistance-associated variants at NS5A-L31 in three of 22 patients. The three patients received DCV plus SOF and eventually obtained SVR12. Second, even if the patient lived in a village other that in which the main hospital building was located, a nurse was designated to be responsible for medication dispensation and compliance. Further, we made every effort and were able to guarantee superior compliance of our hospital patients. In this study, there was no statistically significant difference in treatment outcomes between patients in the two hos- pitals. However, patients from the Chonnam National University Hospital showed a relatively low SVR rate (88.6\%). This may be because some patients in the Chonnam National University Hospital received DAA without a confirmed RAS test, and thus, more patients showed treatment failure on previous antiviral therapy. ${ }^{30,32}$

In genotype 2 patients without liver cirrhosis, the 12-week combination regimen of SOF and ribavirin in the FISSION study showed a 97\% SVR acquisition rate. ${ }^{33}$ Kao et al. ${ }^{34}$ reported a 100\% (87/87) SVR achievement rate in Taiwanese patients receiving SOF plus RBV. In a study conducted by Kim et al., ${ }^{35}$ the SVR rate reached $98.8 \%(161 / 163)$, proving that SOF plus ribavirin combination therapy for Korean patients is remarkably effective. However, some studies have reported limitations to the performance of SOF and ribavirin combination therapy. Jacobson et al. ${ }^{36}$ reported that in treatment-experienced patients who were given 12 weeks and 16 weeks of SOF and ribavirin combination therapy, the SVR rates were only 50\% and 73\%, respectively. In the BOSON study, when SOF and ribavirin were administered to patients with cirrhosis, the SVR rate at 16 weeks was only $87 \% .^{37}$ Due to these limitations, the 2018 European Association for the Study of the Liver guideline no longer mentions SOF and ribavirin combination therapy as a treatment option for genotype 2 patients. ${ }^{38}$ However, as in the above mentioned studies, excellent therapeutic effects of SOF plus RBV regimen have been reported. ${ }^{34,35}$ Therefore, conclusions about the limitations of the SOF and RBV combination therapy may be premature at this time.

In this study, though there was no statistically significant difference, the SVR rate was lower at the Sorokdo National Hospital (92.9\%) than that at the Chonnam National University Hospital (100\%). There were two genotype 2 patients with treatment failure at the Sorokdo National Hospital; both showed liver cirrhosis, while one was diagnosed with esophageal varices and had previous treatment history. This patient was treated for 16 weeks, but no cure was achieved. It is unclear as to why the SVR rate in leprosy-affected genotype 2 patients was low in this study. A possible explanation is that many patients in this cohort were older and had cirrhosis. However, such an interpretation may be controversial since there were no significant differences between the two hospitals in baseline values. Insufficient dosage (200 mg less than the KASL guideline-recommended dosage) may have been the most likely cause. Treatment results of patients at the Chonnam National University Hospital were not different from those of the above-mentioned studies conducted by Kao et al. ${ }^{34}$ and Kim et al. ${ }^{35}$

According to the KASL guidelines, the incidence of severe hemolytic anemia requiring transfusion is very low with a standard dose of ribavirin. In this study, however, the incidence of hemolytic anemia did not decrease significantly even after dose reduction; we continued to prescribe the reduced dose of ribavirin. At the Sorokdo National Hospital, the maximal 
changes in hemoglobin level and the number of patients who required ribavirin dose reduction and blood cell transfusion were significantly high $(\mathrm{p}<0.05)$. However, there was a lack of evidence to explain this in relation to dapsone. In this study, only five patients were prescribed dapsone, and one (1/5, 20\%) experienced anemia during the treatment period. Takaki et al. ${ }^{39}$ reported that a pretreatment hemoglobin level $<14 \mathrm{~g} / \mathrm{dL}$ (hazard ratio [HR], 3.56; 95\% CI, 1.48 to 8.53) and age $\geq 55$ years (HR, 2.50; 95\% CI, 1.05 to 5.94) were significantly associated with ribavirin dose reduction. In a subgroup analysis of genotype 2 patients, the basal hemoglobin level was $12.20 \pm 1.78 \mathrm{~g} / \mathrm{dL}$ and $13.40 \pm 1.16 \mathrm{~g} / \mathrm{dL}(\mathrm{p}=0.055)$, and the mean age was $75.68 \pm 7.18$ years and $69.10 \pm 5.29$ years $(p=0.090)$ at the Sorokdo National Hospital and the Chonnam National Hospital, respectively. The percentage of patients with basal hemoglobin level $>14 \mathrm{~g} /$ dL was significantly lower at the Sorokdo National Hospital (14.3\% vs $42.1 \%, \mathrm{p}=0.015$ ) (Table 1 ). It is possible that the older age and lower hemoglobin levels of patients at the Sorokdo National Hospital may have resulted in the higher incidence of ribavirin-induced hemolytic anemia in these patients. However, there were no statistically significant differences in mean age and basal hemoglobin levels between the two hospitals. Further investigation is necessary to understand the reason for the high incidence of hemolytic anemia in leprosy-affected patients.

Foster et $a{ }^{40}{ }^{40}$ reported that a 12 -week SOF and velpatasvir combination therapy was superior to SOF and ribavirin in genotype 2 hepatitis C patients. The SVR rates were 99\% and 94\% $(p=0.02)$, respectively. Recent reports on the ENDURANCE-2 trial concluded that the SVR rate in all genotype 2-infected patients treated for 12 weeks (including SOF-experienced patients) was 99.5\% with no virologic failure. ${ }^{41}$ Accordingly, we suggest the use of glecaprevir/pibrentasvir or SOF/velpatasvir to prevent ribavirin-induced hemolytic anemia in genotype 2 hepatitis $\mathrm{C}$ patients affected by leprosy.

This study has some limitations. First, because the study only targeted patients admitted to a single center, selection bias could be present. We did not investigate the prevalence of hepatitis $\mathrm{C}$ in all leprosy-affected persons living in South Korea because only patients who visited the Sorokdo National Hospital were included; therefore, these results cannot be generalized to all leprosy-affected persons. Second, although our study shows no statistical difference in SVR rates between two hospitals, the sample size was too small to reach a concrete conclusion. Additionally, due to the small sample size, independent risk factors for ribavirin-induced hemolytic anemia could not be identified. Further investigation is needed in more leprosy-affected hepatitis C patients.

In conclusion, this study was conducted in the largest Korean settlement with domestic leprosy-affected persons; the results of this study can help gastroenterologists in deducing the anticipated treatment course and the plausible status of hepatitis C infection in leprosy-affected persons across Korea. Treatment efficacy was not different between the leprosy-affected population and in the general population. However, severe ribavirininduced hemolytic anemia requiring transfusion occurred in $28.5 \%$ of genotype 2 patients. Therefore, we suggest ribavirinfree DAAs for the treatment of genotype 2 hepatitis $\mathrm{C}$ in leprosy-affected persons in the future. Our findings may further help prevent liver cirrhosis and HCC in leprosy-affected persons.

\section{CONFLICTS OF INTEREST}

No potential conflict of interest relevant to this article was reported.

\section{ACKNOWLEDGEMENTS}

This study was supported by grants (CRI 18091-1, CRI 170271) from the Chonnam National University Hospital Biomedical Research Institute.

\section{AUTHOR CONTRIBUTIONS}

Study concept and design: C.H.J., S.K.C. Data acquisition: Y.H.A., H.P. Data analysis and interpretation: Y.H.A., C.H.J., M.J.L., D.H.K., S.B.C. Drafting of the manuscript: Y.H.A. Critical revision of the manuscript for important intellectual content: C.H.J., S.K.C. Statistical analysis: E.C. Obtained funding: C.H.J. All authors approved the final draft of the manuscript submitted to the journal.

\section{ORCID}

Chung Hwan Jun https://orcid.org/0000-0002-7136-8350

Sung Kyu Choi https://orcid.org/0000-0002-6878-3385

\section{REFERENCES}

1. Polaris Observatory HCV Collaborators. Global prevalence and genotype distribution of hepatitis C virus infection in 2015: a modelling study. Lancet Gastroenterol Hepatol 2017;2:161-176.

2. Hu KQ, Tong MJ. The long-term outcomes of patients with compensated hepatitis C virus-related cirrhosis and history of parenteral exposure in the United States. Hepatology 1999;29:13111316.

3. Fattovich G, Giustina G, Degos F, et al. Morbidity and mortality in compensated cirrhosis type C: a retrospective follow-up study of 384 patients. Gastroenterology 1997;112:463-472.

4. Westbrook RH, Dusheiko G. Natural history of hepatitis C. J Hepatol 2014;61:S58-S68

5. Petruzziello A. Epidemiology of hepatitis B virus (HBV) and hepatitis $\mathrm{C}$ virus (HCV) related hepatocellular carcinoma. Open Virol J 2018;12:26-32

6. Chung YS, Choi JY, Han MG, et al. A large healthcare-associated 
outbreak of hepatitis C virus genotype 1a in a clinic in Korea. J Clin Virol 2018;106:53-57.

7. Sulkowski MS. Anemia in the treatment of hepatitis C virus infection. Clin Infect Dis 2003;37:S315-S322.

8. Sulkowski MS, Wasserman R, Brooks L, Ball L, Gish R. Changes in haemoglobin during interferon alpha-2b plus ribavirin combination therapy for chronic hepatitis C virus infection. J Viral Hepat 2004;11:243-250.

9. Bodenheimer HC Jr, Lindsay KL, Davis GL, Lewis JH, Thung SN, Seeff LB. Tolerance and efficacy of oral ribavirin treatment of chronic hepatitis C: a multicenter trial. Hepatology. 1997;26:473-477.

10. Weiss K. Safety profile of interferon-alpha therapy. Semin Oncol 1998;25:9-13.

11. Fried MW, Hadziyannis SJ. Treatment of chronic hepatitis $C$ infection with peginterferons plus ribavirin. Semin Liver Dis 2004;24:47-54.

12. Manns MP, McHutchison JG, Gordon SC, et al. Peginterferon alfa2b plus ribavirin compared with interferon alfa-2b plus ribavirin for initial treatment of chronic hepatitis $\mathrm{C}$ : a randomised trial. Lancet 2001;358:958-965.

13. Yeon JE. Recent update of the 2017 Korean Association for the Study of the Liver (KASL) treatment guidelines of chronic hepatitis C: comparison of guidelines from other continents, 2017 AASLD/ IDSA and 2016 EASL. Clin Mol Hepatol 2018;24:278-293.

14. Korean Association for the Study of the Liver. KASL clinical practice guidelines: management of hepatitis C. Clin Mol Hepatol 2016;22:76-139.

15. Kim BK, Jang ES, Kim JH, et al. Current status of and strategies for hepatitis C control in South Korea. Clin Mol Hepatol 2017;23:212-218.

16. Suh DJ, Jeong SH. Current status of hepatitis C virus infection in Korea. Intervirology 2006;49:70-75.

17. Kwon GY, Lee H, Gwack J, Lee SW, Ki M, Youn SK. Regional distribution of hepatitis $\mathrm{C}$ virus infection in the Republic of Korea, 2007-2011. Gut Liver 2014;8:428-432.

18. Choi JP, Lee KS, Lee YJ, Lee CH. Hepatitis C in Leprous patients: genotype and risk factor study. Korean J Med 2006;70:11-16.

19. Choi SH. The prevalence of hepatitis $C$ virus infection in leprous patients. Korean J Gastroenterol 1997;30:486-494.

20. Choi SJ, Kim JW, Kim JP. Status of hepatitis C of Hansen's disease of Jeonbuk province. Korean Lepr Bull 2013;46:63-72.

21. Jung K. A proposal for reforming the Hansen's disease control policy. Sejong: Ministry of Health and Welfare, 2018.

22. Guragain S, Upadhayay N, Bhattarai BM. Adverse reactions in leprosy patients who underwent dapsone multidrug therapy: a retrospective study. Clin Pharmacol 2017;9:73-78.

23. Deps P, Guerra P, Nasser S, Simon M. Hemolytic anemia in patients receiving daily dapsone for the treatment of leprosy. Lepr Rev 2012;83:305-307.

24. Egawa K, Yukawa T, Arakawa S, et al. Hepatitis C virus antibody, viral RNA and genotypes in leprous patients in Japan. J Hepatol 1996;24:397-402.

25. Tanaka M, Nishino H, Gaku K, Egawa K, Ozawa T. Survey of the antibody to HCV in National Leprosarium Suruga. Nihon Rai Gakkai Zasshi 1992;61:88-91.

26. Seong MH, Kil H, Kim YS, et al. Clinical and epidemiological features of hepatitis C virus infection in South Korea: a prospective, multicenter cohort study. J Med Virol 2013;85:1724-1733.

27. Nath I, Saini C, Valluri VL. Immunology of leprosy and diagnostic challenges. Clin Dermatol 2015;33:90-98.

28. Fischer M. Leprosy - an overview of clinical features, diagnosis, and treatment. J Dtsch Dermatol Ges 2017;15:801-827.

29. Manns M, Pol S, Jacobson IM, et al. All-oral daclatasvir plus asunaprevir for hepatitis C virus genotype $1 \mathrm{~b}$ : a multinational, phase 3, multicohort study. Lancet 2014;384:1597-1605.

30. McPhee F, Suzuki Y, Toyota J, et al. High Sustained virologic response to daclatasvir plus asunaprevir in elderly and cirrhotic patients with hepatitis C Virus genotype $1 \mathrm{~b}$ without baseline ns5a polymorphisms. Adv Ther 2015;32:637-649.

31. Kao JH, Lee YJ, Heo J, et al. All-oral daclatasvir plus asunaprevir for chronic hepatitis C virus (HCV) genotype $1 \mathrm{~b}$ infection: a subanalysis in Asian patients from the HALLMARK DUAL study. Liver Int 2016;36:1433-1441.

32. Sarrazin C. The importance of resistance to direct antiviral drugs in HCV infection in clinical practice. J Hepatol 2016;64:486-504.

33. Lawitz E, Mangia A, Wyles D, et al. Sofosbuvir for previously untreated chronic hepatitis C infection. N Engl J Med 2013;368:1878-1887.

34. Kao JH, Chien RN, Chang TT, et al. A phase 3b study of sofosbuvir plus ribavirin in Taiwanese patients with chronic genotype 2 hepatitis C virus infection. Liver Int 2016;36:1101-1107.

35. Kim YM, Kim SB, Song IH, et al. Efficacy and safety of sofosbuvir plus ribavirin for Korean patients with hepatitis $\mathrm{C}$ virus genotype 2 infection: a retrospective multi-institutional study. Clin Mol Hepatol 2018;24:311-318.

36. Jacobson IM, Gordon SC, Kowdley KV, et al. Sofosbuvir for hepatitis C genotype 2 or 3 in patients without treatment options. $\mathrm{N}$ Engl J Med 2013;368:1867-1877.

37. Foster GR, Pianko S, Brown A, et al. Efficacy of sofosbuvir plus ribavirin with or without peginterferon-alfa in patients with hepatitis $\mathrm{C}$ virus genotype 3 infection and treatment-experienced patients with cirrhosis and hepatitis $\mathrm{C}$ virus genotype 2 infection. Gastroenterology 2015;149:1462-1470.

38. European Association for the Study of the Liver. EASL recommendations on treatment of Hepatitis C 2018. J Hepatol 2018;69:461-511.

39. Takaki S, Tsubota A, Hosaka T, et al. Factors contributing to ribavirin dose reduction due to anemia during interferon alfa2b and ribavirin combination therapy for chronic hepatitis C. J Gastroenterol 2004;39:668-673.

40. Foster GR, Afdhal N, Roberts SK, et al. Sofosbuvir and velpatasvir for HCV genotype 2 and 3 infection. N Engl J Med 2015;373:2608-2617.

41. Asselah T, Kowdley KV, Zadeikis N, et al. Efficacy of glecaprevir/ pibrentasvir for 8 or 12 weeks in patients with hepatitis c virus genotype 2, 4, 5, or 6 infection without cirrhosis. Clin Gastroenterol Hepatol 2018;16:417-426. 